\title{
Review of the textbook by W.N. Platonov: System of athlete's preparation in Olympic sport. General theory and practical implications (Volume I)
}

\author{
by

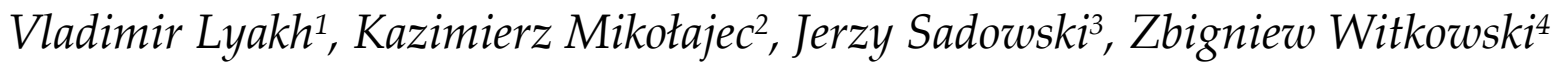 \\ Dariusz Gierczuk ${ }^{3}$, Karol Gryko
}

One of the most extended textbooks that was published recently was written by Platonov, who attempted to provide comprehensive insights into various systems of athlete's preparation in Olympic sports. The textbook is comprised of two volumes. The first volume is composed of 8 parts and 32 chapters. The present review is devoted to the analysis of the material contained in the first volume.

The fifteen-year explorations started by Platonov in 2000 resulted in writing the study which is of vital scientific and practical importance. The necessity of writing this study was justified by the authors by the following:

- significant changes in sports practice, emergence of a number of facts that required scientific analysis and verification, the need for implementation of new components into sports theory and methodology, which emerged with extensive professionalization and commercialization of Olympic sports;

- increasing social and political importance of sports success in the Western countries;
- active participation of the governmental bodies, commercial structures, industrial companies and scientific centres in the development of Olympic sports;

- changes in the policy of the International Olympic Committee, concerning the programme of the Olympic Games through implementation of new sports and women's participation in the sports which used to be considered as men's sports;

- significant elongation of the duration of athletic careers ranging from 20 to 30 years in many sports, which require a more comprehensive approach to the problems connected with athlete's health

(the study discusses the problems of injury rates and diseases, overreaching, overtraining and excessive overloading to the functional systems in the human body).

Platonov explorations have been based on scientifically verified knowledge and information leading to the bests sports results.

1 - Department of Theory of Sport and Kinesiology, Academy of Physical Education in Cracow, Poland.

2 - Department of Team Sport Games, Academy of Physical Education in Katowice, Poland.

3 - Department of Sports Theory and Technology of Sports Training, University of Physical Education in Warsaw, Faculty of Physical Education and Sport in Biata Podlaska, Poland.

4 - Institute of Physical Education, Tourism and Physiotherapy, University in Czestochowa, Poland.

5 - Department of Athletics and Team Sport Games, University of Physical Education in Warsaw, Poland. 
In the chapters devoted to the problems of adaptations of muscle tissue, bone tissue, ligamentous tissue (ensuring energy supply for proper muscle functioning), sports injuries and other, Platonov used first and foremost the data of the experts from Scandinavian countries, Germany, Italy, USA, Canada, Spain and France. In the material concerning preparation of the athlete, the methodology of structuring various components of the training process, sports periodization and coaching aimed to reach the highest skill level, Platonov research was based primarily on the studies written by experts from the Eastern European countries, supplemented with the most recent data derived from studies published by Western researchers.

Of several thousand publications in recent years devoted to the analysis of the optimal preparation of elite athletes, Platonov chose and analysed around $40 \%$ studies.

The substantial part of the contents of the textbook focused on the author's finding and the results obtained by his numerous students, presented in 70 doctoral dissertations. Especially interesting are the results of the studies concerning the strategy of Olympic preparation, scientific, methodological and organizational problems connected with the training process in both individual and team sports. This concerns the programs which were successful during the Olympic Games in 1976-2014.

In the first part of the textbook, composed of two chapters, Platonov discusses the history of the development of the general theory concerning preparation of elite athletes (Chapter 1) and methodology of planning and implementation of training based on modern scientific accomplishments (Chapter 2). Analysis of the systems of athletes' preparation was started by Platonov from preparation of athletes for the Olympic Games in ancient Greece, moving to the second half of the 19th century, when first attempts to organize modern knowledge in this field of science were made. The final portion of this discussion contains the factors which lay foundations for the system of contemporary knowledge about preparation of elite athletes. The author also presented scientific centres and the most important people from various countries with the highest contribution to this process.

According to Platonov, from the methodological standpoint, the theory of athletes' preparation involves various areas and sports. It concerns a significant amount of empirical and practical information from various sports, collected using various scientific methods. The structure of the theory of athletes' preparation was presented by Platonov in Figure 1.

The central part (core, paradigm) of the theory is formed through construction of basic concepts, regularities and principles which, at the major stage of its development, were sufficiently generalized and invariable. The core of the theory is based on a large collection of information included into the peripheral part, concerning a number of facts, hypotheses, ideas, judgements, exceptions and paradoxical phenomena in sports theory and practice and other areas of research (anatomy, physiology, pedagogy, genetics, sports methodology etc.), including various scientific fields, approaches and theories (theory of adaptation, system approach, cybernetics, theory of functional systems etc.). As emphasized by Platonov, knowledge related to the peripheral part was constantly evolving, part of new ideas was developing and adopting an important place in the structure of the theoretical knowledge while others were eliminated.

Using selected examples, the author demonstrated that "any attempts to lay separate foundations and the related principles for the theory are counterproductive and substantially reduce the capabilities of the theory".

In the second chapter, Platonov also isolated 6 functions of the general theory of athletes' preparation (descriptive, explanatory, systematizing, predictive, critical and methodological) and emphasized the importance of an accurate use of the concepts and terms that related to this area. Finally, the author analysed in detail the contemporary system of knowledge concerning the general theory of athletic training at five levels (Figure 2) while revealing the knowledge differentiation in this area (especially at the first level).

Experts will undoubtedly find it interesting to familiarize with Platonov's opinions concerning the two fundamental scientific schools of thought: Eastern and Western. The study contains information concerning the competing nature and mutual interrelations between the preferred training systems related to Olympic 
performance of athletes from the USSR, GDR, USA and other countries.

At the end of Chapter 2, Platonov listed 15 objectives for improvement in the system of athletes' preparation.

The second part of the textbook was presented in Chapters 3 to 5 .

In this part, the author presents classification of sports with division into 6 groups based on specific training and participation in competitive sports. Platonov also discusses other types of division, with their major criteria being the content of the summer and winter Olympic programmes and characterization of the sports on these programmes. Historians of the Olympic movement may find it interesting to familiarize with the analysis of disciplines and events across various sports on summer Olympic programmes (1896 - 1912, 1920 - 1948, 1952 - 1980, 1984 - 2016) and winter Olympic programmes (1992 - 2014).

In Chapter 4, Platonov describes events and disciplines in the Olympic sport. In our opinion, the most attractive content for experts is the analysis of the number of competitions in various Olympic sports (Table 1 ).

While referring to a number of foreign authors (Gudger, Shaal) Platonov emphasized that the practice of the recent decades showed that too frequent and spontaneous participation of an athlete in competitions made it hard to organize optimal planning and implementation of training plans, disturbed basic relationships and principles and lead to overreaching and overtraining, elevated injury risks, lack of predictive capabilities, unsteady results, conflicts with coaches and disappointment of friends and parents.

The experience of the recent years has indicated that the effective preparation for major sporting events in the year round training cycle, assuming the achievement of the best results, is possible only if optimal relations are maintained between the load over the training process and the number of starts. In various sports (except for team sports), the optimal number of official competitions at different levels varies from 10 to 15 , with the number of days of competitions ranging from 25 to 35 (Platonov, 2013).

Furthermore, Platonov discusses the variants of determination of results in events across various sports, conditions of sporting events that have an effect on start (specific properties of the location of the competitions, behaviour of fans, equipment and facilities in the location, geographical and climatic conditions, character and type of judging, behaviour of coaches).

The final part of Chapter 4 presents the material concerning the role and place of competitions within the system of preparation at various levels of sports skill. Platonov listed three approaches with respect to competitions in contemporary sports practice. The first approach assumes athletes' striving for frequent starts and reaching a high level of achievement in the competitions. The other approach adopts a lowintensity start activity, with the substantial focus of an athlete on preparation for the major competitions in the competitive period. In the third variant (approach), the number of competitions is high but the participation in the competitions is carefully adjusted. The author notes that additional competitions are also considered as a component of the preparation process. In such competitions, the athlete is not expected to show a high level of achievement and the whole "system of preparation is oriented towards achievement of high performance in the preliminaries and major sporting events". In the conclusion, Platonov discusses positive and negative aspects of each variant (approach) and analyses the specific nature of the start activity in team sports.

In conclusion of the first part of the review, it should be emphasized that the reader will find all 32 chapters of the book very interesting. The contents represent valuable material with great practical implications for coaches, athletes and research workers. The text is supported by numerous illustrations that make the book more attractive and easier to follow.

The review of the second volume will be presented in a later issue of the JHK.

In Chapter 6, Platonov analyses all aspects related to competitive activity in sport, such as results of the competition plan, its strategy, tactics, structure and control.

The third part of the textbook "Fundamentals of the general theory of athletes' preparation" is composed of seven chapters. Chapter 6 discusses the problems of athlete's body adaptation: types of adaptation (genotypic, phenotypic, immediate, long-term, overadaptation, readaptation, deadaptation); 
athletic load and adaptation; versatility and variants of adaptations in sport; functional reserves and responses connected with adaptation. All these aspects are explained by Platonov considering the theory of functional systems by Anochin and based on the contemporary biochemical and physiological knowledge (at the level of cells, tissues, organic level and systematic level of the entire body).

\section{Central part}

(core, paradigm): concepts, regularities, principles, conceptual and terminological framework

\section{Peripheral part}

ideas, facts, judgements, hypotheses, alternative approaches, exceptions, paradoxical phenomena etc.

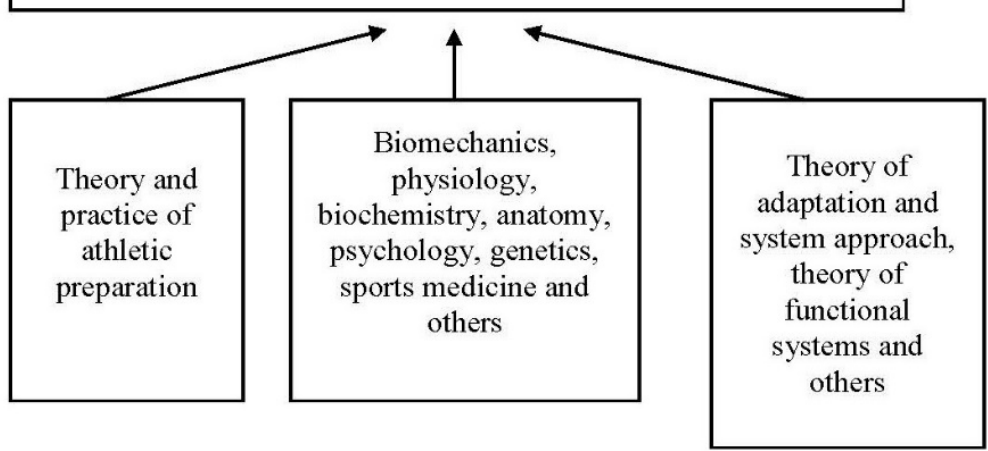

Figure 1

Structure of the theory of athletes' preparation

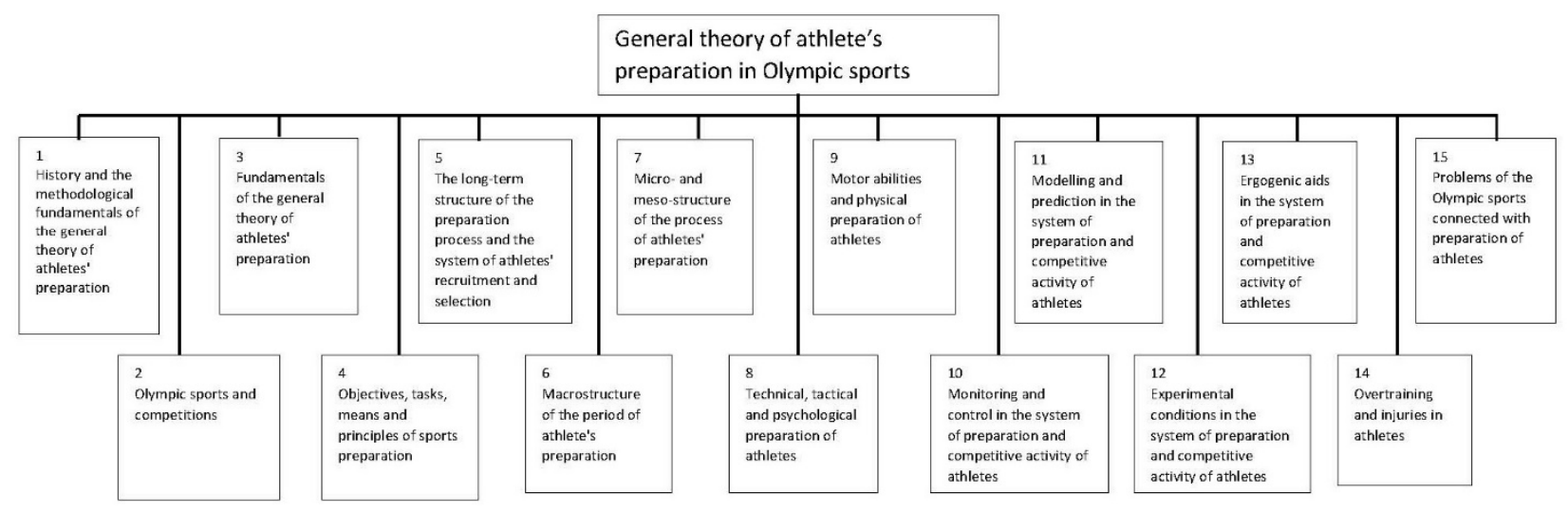

Figure 2

Knowledge differentiation in the area of the general theory

of athletes' preparation at the first hierarchical level (in a separate file) 
Table 1

Number of days of official events and single performances in elite athletes within the annual cycle of preparation.

\begin{tabular}{|c|c|c|c|c|c|}
\hline Sport & $\begin{array}{c}\text { Number of } \\
\text { days of } \\
\text { competitions }\end{array}$ & $\begin{array}{l}\text { Number of } \\
\text { single } \\
\text { performances }\end{array}$ & Sport & $\begin{array}{c}\text { Number of } \\
\text { days of } \\
\text { competitions }\end{array}$ & $\begin{array}{l}\text { Number of } \\
\text { single } \\
\text { performances }\end{array}$ \\
\hline $\begin{array}{l}\text { artistic } \\
\text { gymnastics }\end{array}$ & $20-30$ & $150-200$ & table tennis & $75-80$ & $380-420$ \\
\hline diving & $20-30$ & $250-320$ & water polo & $50-55$ & $70-85$ \\
\hline fencing & $30-40$ & $415-480$ & handball & $70-80$ & $70-80$ \\
\hline high jump & $35-45$ & $120-180$ & $\begin{array}{l}\text { freestyle } \\
\text { wrestling }\end{array}$ & $30-40$ & $50-70$ \\
\hline long jump & $35-45$ & $120-180$ & $\begin{array}{l}\text { Greco-Roman } \\
\text { wrestling }\end{array}$ & $30-40$ & $50-70$ \\
\hline hammer throw & $35-45$ & $120-180$ & boxing & $25-30$ & $25-30$ \\
\hline $\begin{array}{l}\text { sprints }(100 \mathrm{~m} \\
\text { and } 200 \mathrm{~m} \text { races })\end{array}$ & $22-26$ & $28-32$ & weightlifting & $10-12$ & $50-77$ \\
\hline $\begin{array}{l}\text { middle-distance } \\
\text { events }(800 \mathrm{~m} \\
\text { and } 1500 \mathrm{~m})\end{array}$ & $20-25$ & $20-25$ & skiing & $30-40$ & $30-40$ \\
\hline $\begin{array}{l}\text { long-distance } \\
\text { events }(5000 \mathrm{~m} \\
\text { and } 10,000 \mathrm{~m})\end{array}$ & $15-20$ & $15-20$ & biathlon & $25-30$ & $25-30$ \\
\hline marathon race & $4-6$ & $4-6$ & $\begin{array}{l}\text { cross-country } \\
\text { skiing }\end{array}$ & $30-40$ & $30-40$ \\
\hline $\begin{array}{l}\text { association } \\
\text { football }\end{array}$ & $70-85$ & $70-85$ & speed skating & $40-50$ & $40-50$ \\
\hline
\end{tabular}

* single performance - participation in a gymnastic event competition, a fencing or wrestling match, an attempt in jumping events, a football match.

Chapter 7 of the textbook is entitled "Human ontogenetic development and formation of adaptations". In this chapter, the author cites interesting data related to periodization of human ontogenetic development that consists in changes occurring in the bone tissue, muscle tissue and adipose tissue, and the nervous system in untrained children, teenagers and young athletes. The author discusses such problems as sensitive periods, emphasizes scientific facts concerning the energy pathways and changes occurring in these systems with age and depending on sex. The textbook also indicates how the level of recovery capabilities and tolerance to training loads change, to which degree work economy depends on the age and provides information about changes in the range of muscle strength and flexibility.
The title of Chapter 8 is "Skeletal muscles". The author uses colourful figures to present the structure of the skeletal muscles, mechanisms of muscular contraction, changes occurring in muscle fibres caused by the load with different magnitude and character; coordination of work of motor units as an important mechanism of muscle adaptation to physical loads. He also presents the types of adaptive changes in bone tissue and connective tissue caused by various factors, including physical loads. Chapter 9 illustrates changes in the oxygen transport system (respiratory system, cardiovascular system, blood parameters) due to the increasing muscle activity. Colourful figures enhance understanding of the role of particular systems in functional improvement of athlete's performance.

Chapter 10 is entitled „Energy pathways for 
ensuring muscle work". The author discusses various data which are important to coaches and athletes, related to adjustment of the level of exercise during work with specific volume and intensity, various psychical strain and coordination complexity; anaerobic and aerobic systems of energy generation in untrained people and athletes from different sports: cyclic, acyclic, speed and strength sports, team sports and combat sports.

In Chapter 11, Platonov describes the development of knowledge in terms of such problems as training loads and competitive loads, active and passive recovery in the work-recovery systems; specific nature of adaptive responses of the athlete's body to any loads; the effect of loads on the athlete's body depending on the level of sports skill and stage of preparation; role of fatigue and recovery process efficiency depending on the level of fitness and skills; super-compensation and long-time delayed training effect.

Chapter 12, "Fundamentals of movement control and regulation", contains significant information about the role of the nervous system in the processes of motor control and regulation. The data presented by the author show that the improvement in the area of motor abilities may have an important impact on the level of special fitness. The author refers to the findings published by world-renowned researchers (Bersztejn, Uhtomski, Anochin, Donskoj, Czhaidze and others). He also presents the basic theory related to the development of technical skills.

The fourth part of the textbook, composed of Chapters 13 and 14, reflects the basic aspects of athletic preparation: goal, task, means, methods and principles. These traditional problems of sports training do not have to be additionally discussed since they have been analysed in other similar publications. What should be emphasized is a slightly different approach of the author to general and special principles of athlete's preparation. The first group included:

- focus on peak performance,

- advanced sport-specific training,

- consistency between general preparation and sport-specific training,

- continuity of the training process,

- gradual increment in the level of loads until maximal values are reached,

- proper sports periodization,

- load variants,

- cyclic preparation process,

- adequate ratio of training loads to competitive loads.

The second group included:

- effect of lifestyles on the quality and efficiency of the training process and competitive performance,

- adequate integration of prevention programs into the training process and competition schedules.

The fifth part of the textbook is entitled "The structure of the preparation process and stagebased system of recruitment and orientation in sport". Chapter 15 discusses long-term training, approached as a system of knowledge, which was formed gradually from classic Russian, Soviet and German studies published in the 60s and 70s of the 20th century by Ozolin, Harre, Nabatnikowa and Filin through to contemporary authors (Haff, Wiliams, Olbrecht, Olisk).

In Chapter 16, entitled "Construction fundamentals of long-term training programs", Platonov discusses:

- optimal age for initiation of various sports,

- aptitudes for practising specific sports,

- main objectives for intensification of the training process and importance of specific training,

- time of preparation for peak performance,

- variants of development aimed to achieve the elite level,

- importance of competitions within a multiannual athlete's development program,

- role of competition at individual stages of coaching and problem of using intensive rather than progressive training,

- dynamics of changes in basic indices of the training process in athletes from various sports over a four-year Olympic cycle,

- characteristics of annual program periodization at various stages of long-term preparation,

- effect of long-term breaks in the training process,

- effect of the environment on training efficiency.

Chapter 17 of the textbook, entitled "Contemporary training periodization system" and 
Chapter 18 "Recruitment and orientation in the system of multiannual preparation" contain the material from the previous book written by the author ("Sports training periodization"), presented in respective Chapters 13 and 14 .

The sixth part "Macrostructure of the process of athletes' preparation" was presented in seven chapters.

In Chapter 19 "Periodization of the athletes' annual preparation. History of development", Platonov discusses the history of the periodization theory and provides a brief description of the concept of periodization of the annual cycle by Matwejew and its further development. Chapter 20 presents a critical discussion of the views of various researchers concerning Matwejew's theory, models and concepts of periodization of the annual training cycle developed by Werchoszanski, Worobjew, Bondarczuk, Issurin, Plisk, Kremer, Fleck, Sift, Baker, Stone, Bompa, Lambert, Mujika, Haff and others. In Chapter 21, the author analyses the problem of the annual cycle in the context of long-term training programs. The chapter discusses the most important periodization strategy in the annual cycle with one-, two- and three-cycle models of periodization and the importance of competitions in the periodization of annual preparation.

Chapter 22 presents the experiences of the experts from GDR and USSR concerning periodization of annual preparation, whereas Chapter 23 attempts to explain American and Australian experiences. Chapter 24 contains comprehensive material concerning contemporary models of periodization of the annual preparation plan in selected sports, including team sports. These models are presented by Platonov as three-, five-, six- and seven-part constructs. The sixth part of the book ends with Chapter 25. The title of this chapter is "Direct preparation for competition". Among other things, the author discusses such fundamental problems as training in the precompetitive mesocycle, pre-competitive preparation for a single competition or direct preparation for a series of competitions.

The seventh part of the textbook is entitled "Micro and mesostructure of the process of athlete's preparation". In Chapter 26, the author provides brief characteristics of modern approach to the warm-up (structure, content, specific nature of the warm-up before competition and other problems). Chapter 27 explains the properties of organization, contents and types of training units, their structure across various sports and problems of annual and long-term preparation. Chapter 28 illustrates the idea of microcycles and their structure in various sports. Furthermore, Chapter 29 concerns the concept of mesocycles (types, volume and intensity) and dynamics of training loads, integration of microcycles into mesocycles, specific planning of mesocycle in women's training. The content of Chapters 17 to 29 was discussed in details in previous publications that have reviewed Platonov's accomplishments in sports theory and practice (Lyakh et al., 2014, 2015, 2016).

In the eighth part of the textbook, Platonov discusses fundamentals of technical, tactical and psychological preparation of elite athletes. This part is composed of three chapters (Chapters 30, 31 and 32). The first of them formulates questions concerning tasks, resources and methods of technical preparation, its stages and differentiation due to the sports level. Problems of technical and tactical preparation were discussed in Chapter 31. The last chapter (Chapter 32) explains all the aspects of mental readiness and psychological preparation of athletes; mental traits and objectives of psychological preparation, problems of motivation, volitional preparation; building selfconfidence, visualization training and self-talk, perception, control over emotional distress, overcoming anxiety and depression, tolerance for emotional distress, control of competitive states, efficiency of teamwork.

\section{Corresponding author:}

\section{Kazimierz Mikołajec,}

Department of Team Sport Games, Academy of Physical Education in Katowice

Mikołowska 72A, 40-065 Katowice, Poland

Phone: +48322075236

E-mail: k.mikolajec@awf.katowice.pl 